\title{
Imposto de Renda: função contínua? Uma questão de Cálculo tanto para o Ensino Básico quanto para o Ensino Superior
}

\author{
Income Tax: continuous function? An issue of calculus for both High School and \\ Higher Education
}

\author{
Eliane Bihuna de Azevedo ${ }^{1}$ \\ Elisandra Bar de Figueiredo ${ }^{2}$ \\ Ivanete Zuchi Siple ${ }^{3}$ \\ Pedro Manuel Baptista Palhares ${ }^{4}$
}

\section{Resumo}

Um conteúdo que gera debates entre professores e pesquisadores de Cálculo Diferencial e Integral (CDI) é a definição de continuidade de uma função real de uma variável real. Nesse sentido, este texto apresenta e discute a diferença entre duas definições de continuidade que aparentemente pode ser sutil, porém veremos que não é. Também apresentamos essa discussão numa atividade proposta aos alunos de um Programa de Pós-Graduação em Ensino de Ciências, Matemática e Tecnologia da Universidade do Estado de Santa Catarina (PPGECMT/UDESC) no contexto do imposto de renda. A metodologia utilizada para aplicação das atividades foi a Resolução de Problemas. Os resultados oriundos das discussões dessa atividade evidenciam que essas atividades poderão ser utilizadas tanto nas aulas de Matemática do Ensino Médio quanto nas aulas de CDI do Ensino Superior e poderão auxiliar um (futuro) professor de Matemática na percepção das conexões existentes entre os conteúdos estudados no Ensino Superior com os do Ensino Básico, pois muitas vezes esse elo entre esses dois níveis de ensino não é perceptível aos estudantes nem aos professores de CDI.

Palavras-chave: Educação Matemática. Cálculo diferencial e integral. Resolução de problemas. Função contínua. Imposto de renda.

\section{Introdução}

\footnotetext{
${ }^{1}$ Mestre, professora, Universidade do Estado de Santa Catarina, eliane.bihuna@gmail.com

${ }^{2}$ Doutora, professora, Universidade do Estado de Santa Catarina, elis.b.figueiredo@gmail.com

${ }^{3}$ Doutora, professora, Universidade do Estado de Santa Catarina, ivazuchi@gmail.com

${ }^{4}$ Doutor, professor, Universidade do Minho, palhares@ie.uminho.pt
} 
Esse artigo apresentará algumas discussões sobre o Ensino de Cálculo no Ensino Médio realizadas na disciplina de Fundamentos do Cálculo (FCA) do Mestrado Profissional em Ensino de Ciências, Matemáticas e Tecnologias (PPGECMT) da Universidade do Estado de Santa Catarina (UDESC). Essa disciplina tem como objetivos reconhecer, refletir e aprofundar as ideias fundamentais do Cálculo, em termos de teoria e práticas, objetivando compreender os elos que ligam os conteúdos da Matemática Superior com a Educação Básica, propiciando oportunidades que possam enriquecer a formação do Professor necessária à prática docente.

Nessa perspectiva apresentamos uma atividade a respeito de continuidade de uma função, assunto de Cálculo Diferencial e Integral (CDI), que pode ser abordada tanto no contexto de Ensino Médio (EM) como do Ensino Superior (ES), podendo ser mediada pela metodologia de Resolução de Problemas (RP). Essa atividade foi amplamente discutida com a professora e com os alunos da disciplina de FCA.

Com o intuito de apresentar as discussões oriundas no desenvolvimento desse trabalho o estruturamos da seguinte forma: um breve histórico do Cálculo no EM e da metodologia RP; discussão a respeito da continuidade de uma função; descrição de uma prática composta de duas atividades, para estudar a continuidade da função matemática; considerações finais e referências.

\section{Que metodologia adotar?}

O Cálculo já esteve presente no currículo do Ensino Básico brasileiro por diversas vezes desde o ano 1811 e fez parte do currículo da Academia Real Militar (TORRES; GIRAFFA, 2009), até 1961, com a consolidação do movimento conhecido como Matemática Moderna, que teve início em 1950 (CONCORDIDO; BARBOSA, 2015). A Matemática Moderna foi responsável por significativas mudanças nos currículos, dentre elas a exclusão do Cálculo e a inclusão do excessivo rigor matemático nas apresentações (ÁVILA, 1991). Ávila (1991) fez 
críticas aos reformistas, pois eles desejavam modernizar o ensino, para que a matemática não ficasse limitada ao que fora desenvolvido até o ano de 1700, porém retiraram o Cálculo cujas ideias, apesar de serem anteriores ao século XVII, eram uma das mais inovadoras, em matemática, que existiam na época.

No Brasil, os Parâmetros Curriculares Nacionais para o Ensino Médio (BRASIL, 2000) e as Orientações Curriculares para o Ensino Médio (BRASIL, 2006) e atualmente a versão preliminar da Base Nacional Curricular Comum $(B N C C)^{5}$ de Matemática no Ensino Médio (EM) orientam que os objetivos de aprendizagem e desenvolvimento da componente Matemática não devem ser trabalhados de forma fragmentada, mas que os conteúdos sejam abordados em todas as unidades curriculares, com ênfases diferentes, visando ampliar o conhecimento matemático dos estudantes. A conexão com o Cálculo Diferencial aparece de forma implícita, nos documentos, no momento em que eles sugerem o estudo de funções, observando que os alunos devem explorar situações problemas que envolvam os conhecimentos de taxa de variação e máximos e mínimos.

A respeito de trabalhar com as ideias fundamentais do Cálculo no EM Ávila (1991), já na década de 90, defendia que é possível, pois acreditava que "a ideia de que os programas de Matemática são extensos e não comportariam a inclusão do Cálculo é um equívoco. Os atuais programas estão, isto sim, mal estruturados" (ÁVILA, 1991, p.4). Entretanto, há a necessidade de repensar a formação inicial dos professores, para que eles consigam estabelecer as conexões existentes entre os conteúdos do Cálculo no Ensino Superior (ES) e as ideias fundamentais a serem exploradas no EM.

A pesquisa de Guedes e Assis (2009, p.1) aponta que "o despreparo dos professores para ensinar Cálculo no EM tem uma relação direta com a metodologia de ensino dessa disciplina nos cursos de Licenciatura em

\footnotetext{
${ }^{5}$ Neste artigo nos apoiamos na segunda versão da BNCC que foi disponibilizada no portal da MEC no dia 03/05/2016. A terceira versão da BNCC está em tramitação. Disponível em: http://basenacionalcomum.mec.gov.br/\#/site/histórico-noticias?noticia=359. Acesso em: 02/03/2017.
} 
Matemática". Esse pensamento entra em consonância com a real necessidade das universidades discutirem quais são os conhecimentos necessários para 0 futuro professor e promoverem ações concretas que possam interferir positivamente na formação dos formadores (SBEM, 2013).

Uma das metodologias de ensino que pode contribuir na formação dos futuros professores é a RP, que tem por finalidade fazer o aluno assumir um papel mais ativo em sua aprendizagem. Nessa perspectiva apresentamos uma atividade a respeito de continuidade de uma função, assunto de CDI, que pode ter abordada tanto no contexto do EM como do ES, podendo ser mediada pela metodologia RP.

\section{Metodologia de Resolução de Problemas}

Em meados do século XX a RP passou a ser vista como uma abordagem metodológica que visa promover uma aprendizagem mais significativa. George Polya é considerado um dos pioneiros no estudo de RP como estratégia de ensino e aprendizagem e destaca a importância de fazer o aluno pensar por meio da RP. Polya, em seu livro ${ }^{6}$ traduzido para o português como "A arte de resolver problemas: um novo aspecto do método matemático", preocupou-se em ensinar estratégias que pudessem levar o aluno a ser um bom resolvedor de problemas. Nesse livro, se apresenta uma sequência de quatros etapas que devem ser seguidas para se obter êxito na resolução de um problema, que são: compreensão do problema, construção de um plano de resolução, execução do plano e revisão da solução (POLYA, 2006).

A entidade norte-americana National Council of Teachers of Mathematics, apresentou o documento "An Agenda for Action" (Uma Agenda para Ação), dizendo que RP deveria ser o foco da matemática escolar nos anos 80, recomendando que os professores de Matemática criassem situações nas salas de aula em que a RP pudesse desabrochar (NOGUTI, 2014).

\footnotetext{
${ }^{6}$ O livro original foi publicado em 1945 com o título How to solve it.
} 
No transcorrer do tempo a proposta de como se trabalhar com a RP passou por várias modificações e surgiram concepções diferentes sobre a forma de abordá-la em sala de aula. Segundo Schroeder e Lester (1989) há três formas de conceber a RP, que consistiam em trabalhar para, sobre ou através da RP.

O Grupo de Trabalho e Estudo sobre RP (GTERP), coordenado pela professora Lourdes de la Rosa Onuchic, na UNESP de Rio Claro, busca desenvolver estudos que efetivamente atinjam a sala de aula, ou seja, que estejam relacionados com questões de ensino-aprendizagem-avaliação tanto sob a perspectiva do aluno quanto do professor. Segundo Onuchic (2013), o GTERP faz uso de uma sugestão de roteiro de atividades, destinado à orientação de professores para a condução de suas aulas que desejam ensinar através da RP: preparação do problema, leitura individual, leitura em conjunto, resolução do problema, observar e incentivar, registro das resoluções na lousa, plenária, busca de consenso e formalização do conteúdo.

Nessa pesquisa adotamos a concepção de ensinar através da RP e buscamos, sempre que possível, utilizar o roteiro de atividades proposto pelo grupo GTERP.

Levando em consideração a importância da proposição de atividades, no Ensino de Cálculo, que possibilita o elo entre o Ensino Básico e o Superior, abordaremos discussões importantes a respeito da continuidade de uma função na prática do (futuro) professor.

\section{Uma discussão interessante: a continuidade de uma função}

Muitos estudantes e, até mesmo, professores quando questionados sobre o que entendem por função contínua acabam associando ao significado literal da palavra continuidade. Pelo dicionário Houaiss (2003), continuidade significa sequência, continuação, dentre outros sinônimos. Diversos livros didáticos de CDI trazem exatamente essa ideia intuitiva de continuidade ao dizerem que o gráfico de uma função contínua não apresenta quebras, interrupções (ANTON, 
2014; STEWART, 2009), ou seja, pode ser representado "sem remover sua caneta do papel" (STEWART, 2009, p.107).

O conteúdo de continuidade de uma função é um assunto que pode gerar discussões entre professores de Cálculo. Entendemos que esses tipos de discussões podem ocorrer, pois, analisando alguns livros didáticos de CDI, é possível encontrar diferenças, que numa primeira impressão podem ser consideradas muito sutis, na definição de continuidade de uma função em um ponto. Diferenças essas que podem até passar despercebidas por iniciantes (tanto estudantes quanto professores) em Cálculo. Jayakody e Zazkis (2015) em seu artigo "Continuous Problem of Function Continuity" fazem uma ampla discussão sobre os problemas que surgem por meio dessas diferenças aparentemente sutis envolvendo o conceito de continuidade.

A continuidade é descrita e definida para atender diferentes públicos em diferentes níveis, incluindo o uso de definições intuitivas, informais, formais e mais rigorosas (definição por épsilon-delta). Geralmente, num primeiro curso de Cálculo, a definição de continuidade está associada com limite. (JAYAKODY; ZAZKIS, 2015, p.9, tradução nossa).

llustraremos as definições de continuidade discutidas no artigo de Jayakody e Zazkis (2015), evidenciado as sutilezas envolvidas nessas definições.

Definição 1 (D1): Uma função $f$ é contínua em $c$ se,

i. $f(x)$ está definida em $x=c$;

ii. $\lim _{x \rightarrow c} f(x)$ existe;

iii. $\lim _{x \rightarrow c} f(x)$ é igual a $f(c)$.

E $f$ é descontínua se alguma das condições acima não for satisfeita.

Essa definição é encontrada em alguns livros de cálculo, tais como: Stewart (2013) e Anton (2000).

Definição 2 (D2): Uma função é dita contínua para $x=c$ pertencente ao seu domínio se, $\lim _{x \rightarrow c} f(x)=f(c)$ e $f$ é descontínua em $x=c$ pertencente ao seu domínio se, $\lim _{x \rightarrow c} f(x) \neq f(c)$.

Essa definição de continuidade é utilizada por Guidorizzi (2008), porém o autor não usa o termo descontinuidade. 
Para apontar as (in)consistências das duas definições considere a função $f(x)=\frac{x^{2}-4}{x-2}$. Observe que para todo $x$ pertencente ao domínio de $f$, tanto pela definição D1 quanto pela definição D2 tem-se que $f$ é contínua para todo $a \neq 2$, pois $\lim _{x \rightarrow a} f(x)=f(a)$. Em $x=2$ a conclusão não é mesma que se obtém usando as definições D1 e D2. Note que, pela definição D1, $f$ é uma função descontínua em $x=2$, pois falha a primeira condição de continuidade nesse ponto. E, por D2, não faz sentido estudar a (des)continuidade de $f$ em $x=2$, pois 2 não está no domínio da função. Portanto, por D1, $f$ é uma função descontínua em $x=2$ e, por D2, $f$ é uma função contínua para todo $x$ de seu domínio.

De acordo com Jayakody e Zazkis (2015), a definição D2 é aceita como sendo mais rigorosa, do ponto de vista de matemáticos; e, a definição D1 é a mais utilizada nos cursos introdutórios de Cálculo. Nas considerações finais de seu artigo, as autoras enfatizam que o professor deve ser coerente com as escolhas feitas; ressaltam que o mesmo conceito não deve conduzir a contradições; e, dizem que professores universitários que ministram Cálculo podem evitar o problema que pode surgir ao apresentar funções definidas em todos os números reais, exceto em um ponto, redefinindo funções da seguinte forma: $f(x)=\left\{\begin{array}{c}\frac{x^{2}-4}{x-2}, \text { se } x \neq 2 \\ 4, \text { se } x=2\end{array}\right.$, por exemplo.

Após a apresentação das discussões que surgem no que se refere a algumas variações na definição de continuidade de uma função, na próxima seção iremos apresentar uma prática referente a esse assunto que aborda um problema real que pode ser utilizado/adaptado para se trabalhar com conteúdos de Cálculo tanto no EM quanto no ES.

\section{Traços de uma prática}

As atividades que serão relatadas nas próximas subseções foram aplicadas na turma de Fundamentos de Cálculo (FCA) no primeiro semestre letivo 
de 2016, com cinco alunos ${ }^{7}$. A primeira atividade foi realizada individualmente e as demais em grupo.

Nessa disciplina não foram utilizados todos os passos recomendados para se trabalhar com a metodologia de RP, pois após a discussão das respostas obtidas pelos grupos, dever-se-ia formalizar o conteúdo de continuidade. Esse fechamento não foi feito, porque todos os alunos já possuíam o conhecimento sobre o assunto, visto que eram todos pós-graduandos com formação inicial em Matemática. Porém, pelos experimentos que a primeira autora vem realizando em suas turmas regulares de CDI, acreditamos que seria possível trabalhar com todas as etapas sugeridas por Onuchic (2014) para adotar a metodologia de RP em sala de aula. A seguir, apresentamos a prática proposta e as discussões oriundas dessa aplicação.

\section{a. Atividade 1 - Investigação Preliminar}

O objetivo da primeira atividade proposta era investigar as concepções iniciais dos alunos sobre continuidade. Assim, abordamos as questões apresentadas no Quadro 1. Para desenvolver a atividade por meio da metodologia de RP, inicialmente, o professor deve entregar as atividades a serem realizadas pela turma de forma individual ou em grupo, sem direcionar (através da fala) o aluno a um assunto específico, pois as atividades propostas pelo professor já foram elaboradas de forma que se alcance o desenvolvimento do conceito que era o objetivo da prática.

\footnotetext{
${ }^{7}$ A primeira autora era uma das alunas da disciplina, na qual propôs e mediou as atividades relatadas nesse artigo.
} 
Quadro 1 - Investigação preliminar

1. Quando você ouve a palavra "continuidade" o que você entende?

2. Dê, ao menos, um exemplo prático de função contínua.

3. A Figura 1 modela a concentração $\mathrm{C}$ de um medicamento na corrente sanguínea de um paciente ao longo de um período de 48 horas. Discuta o significado das descontinuidades no gráfico.

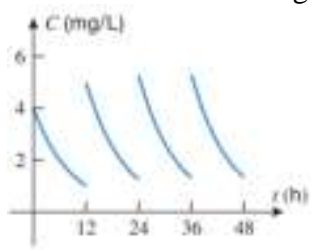

Figura 1 - Concentração de um medicamento na corrente sanguínea.

Fonte: ANTON, 2014, p.118

Fonte: Autoria própria.

Essa atividade foi realizada individualmente, mas poderia ter sido feita em grupos, como é a proposta da metodologia de RP, pois em grupos há uma interação e troca de conhecimentos entre os pares. Durante a realização dessa atividade a professora (primeira autora) não precisou auxiliar nenhum aluno, pois eles fizeram a leitura individual das questões e responderem 0 que entendiam/sabiam sobre o assunto.

Após todos responderem foi feita uma discussão (plenária) de forma oral sobre as questões propostas. Quando questionados a respeito do que você entende ao ouvir a palavra continuidade, surgiram exatamente as ideias intuitivas de função contínua como são apresentadas em diversos livros de cálculo (sessão anterior), ou seja, foi unanime associar continuidade com "algo que continua". Para ilustrar isso, apresentamos a resposta dada por dois alunos: Aluno 1 - "Algo que continua, que segue, que não sofre interrupções. Por exemplo, o tempo."; Aluno 2 "Algo que continua, fluxo, sequência sem interrupções. Refere-se a algo contínuo."

Com relação à segunda questão em que era solicitado um exemplo prático de continuidade, foi possível perceber o quanto a ideia de aplicação, por parte dos egressos de um curso de Licenciatura em Matemática, está associada com aplicações dentro da própria matemática. Pois, como resposta, esperava-se algo prático, como por exemplo, o crescimento de uma pessoa, mas como respostas, foram apresentadas funções na forma sua analítica, dentre elas $f(x)=2+x$, para todo número real. Não deixa de ser verdade, pois como o domínio dessa 
função é o conjunto dos números reais, utilizando qualquer uma das duas definições, conclui-se que $f$ é contínua. Apenas o Aluno 3 deu um exemplo prático. A resposta desse aluno foi "Um carro se movimentando num determinado intervalo de tempo".

Com relação à terceira questão, que estava relacionada com a concentração de um medicamento na corrente sanguínea durante um período de 48 horas, todos os respondentes interpretaram que a medicação era ingerida a cada 12 horas. Resposta do Aluno 2: "Acho que o medicamento é tomado de 12 em 12 horas a ponto de passadas 12 horas ser necessário ingerir novamente $o$ medicamento."

Quanto à continuidade, a função que descreve a concentração do medicamente é contínua para $t \in(0,12) \cup(12,24) \cup(24,36) \cup(36,48)$ independente do uso da definição D1 ou D2. Ainda, por D1, está função é descontínua em $t=12 h, t=24 h, t=36 h$; e, por D2, não tem sentido analisar a descontinuidade nestes valores de $t$.

Ressalta-se que na primeira atividade foi feita a discussão a respeito da continuidade de uma função somente do ponto de vista informal. Depois desse momento, não foi feita nenhuma discussão a respeito da definição formal. Para dar sequência ao trabalho foram formadas duas duplas (escolhidas pelos próprios alunos) para trabalhar com a atividade 2, que está relacionada com o imposto de renda brasileiro e será apresentada na próxima subseção.

\section{b. Atividade 2 - Imposto de renda: função contínua?}

Após as duplas terem sido formadas foram entregues as questões 1 e 2 , apresentadas no Quadro 2. A terceira questão da atividade 2, que era uma modificação da primeira, foi entregue aos grupos quando estavam em fase de conclusão das duas primeiras questões propostas. Essa atividade está relacionada ao cálculo do imposto de renda brasileiro pago por um contribuinte no ano de 2016 referente ao ano de exercício de 2015. 
A atividade 2 aqui apresentada foi adaptada após a aplicação na turma de FCA, pois a versão inicial apresentava um erro na terceira coluna das tabelas progressivas do imposto de renda, mas a discussão gerada e a forma como foi conduzida não foi prejudicada com esse equívoco. Pelo contrário, o erro (que no momento não fora identificado por nenhum dos respondentes nem pela professora) foi responsável por aguçar a curiosidade desses autores em esclarecer a seguinte pergunta: como são obtidos os valores da parcela a deduzir do imposto de renda apresentados nas tabelas 1 e 2, conforme o Quadro 2 ?

Quadro 2 - Questões 1 e 2 da atividade 2 
1. Desde 2007 a Receita Federal tem alterado as bases de cálculo para a declaração do imposto de renda de pessoas físicas, aumentando o intervalo das faixas salariais e da parcela a ser deduzida no cálculo do imposto. Além disso, desde 2009 também foram adotadas duas novas alíquotas, de 7,5\% e 22,5\%, juntamente com as de $15 \%$ e 27,5\% já existentes. Em 2015, houve uma alteração em todas as faixas salariais. As tabelas 1 e 2 evidenciam estas mudanças, mostrando as faixas do imposto de renda de pessoa física, conforme o nível salarial do contribuinte, para os exercícios de 2015 (ano-calendário de 2014) e de 2016 (ano-calendário de 2015), respectivamente.

Tabela 1 - Exercício de 2015, ano-calendário de 2014 até Março de 2015. Base de cilculo mensal (RS) $\mid$ Aliquota (\%) Parcela a Deduzir (RS)

\begin{tabular}{|l|c|c|}
\hline Até $1.787,77$ & - & - \\
\hline De $1.787,78$ até $2.679,29$ & 7,5 & 134,08 \\
\hline De $2.679,30$ até $3.572,43$ & 15 & 335,03 \\
\hline De $3.572,44$ até $4.463,81$ & 22,5 & 602,96 \\
\hline Acima de $4.463,81$ & 27,5 & 826,15 \\
\hline
\end{tabular}

Tabela 2: Exercício de 2016, ano-calendário a partir de Abril de 2015. \begin{tabular}{|l|l|l|l|}
\hline Base de cilculo mensal (RS) & Aliquota (\%) & Parcela a Dedurir (RS)
\end{tabular}

\begin{tabular}{|l|c|c|}
\hline Até $1.903,98$ & - & - \\
\hline De $1.903,99$ até $2.826,65$ & 7,5 & 142,80 \\
\hline De $2.826,66$ até $3.751,05$ & $I 5$ & 354,80 \\
\hline De $3.751,06$ até $4.664,68$ & 22,5 & 636,13 \\
\hline Acima de $4.664,68$ & 27,5 & 869,36 \\
\hline
\end{tabular}

Fonte: http://www.dpc.com.br/pt-br/show/tabela-progressiva-do-imposto-de-renda. Acesso: 14/04/2016

Um contribuinte decidiu analisar com cuidado as tabelas 1 e 2 e entender melhor como é feito o "acerto de contas com o Leão", como é conhecido o pagamento do imposto de renda à Receita Federal. Para calcular o valor a ser pago basta realizar o produto da alíquota pelo salário recebido e descontar a parcela a deduzir. O determinado contribuinte está se questionando se o valor a ser pago de imposto de renda aumenta continuamente conforme o valor de seu salário. Vamos auxiliar esse contribuinte, da seguinte forma:

a. Encontrando qual é a função que descreve o imposto de renda a partir de Abril de 2015.

b. Estudando a continuidade da função obtida no item "a".

2. Suponha que um contribuinte recebeu durante todo o ano de 2015 um salário mensal fixo de $R \$ 3.600,00$. Nessas condições, quanto de imposto de renda esse contribuinte deve ter pago em 2016? Analisando as tabelas 1 e 2, você julga que a nova tabela beneficiou ou não o determinado contribuinte? Por quê?

Fonte: Autoria própria.

Ressalta-se que para a realização dessa atividade recomenda-se que seja utilizada ao menos uma calculadora. É interessante também a utilização de algum software gráfico. Essa recomendação se dá porque as faixas salariais das tabelas referentes ao imposto de renda apresentam números decimais, que dificultam as contas sem uso de algum instrumento tecnológico. Nesse caso, os grupos utilizaram o software GeoGebra.

Para a realização dessa tarefa as duas equipes se envolveram bastante com o problema proposto. De fato, essa atividade realmente foi uma situação problema para os alunos, pois conseguiu despertar o interesse deles e se sentiram desafiados a resolverem (DANTE, 2009). A questão 1 demandou 
relatada das questões 1 e 2 foram realizadas somente após a conclusão da terceira questão.

A terceira questão proposta foi similar a questão 1 , pedia para estudar a continuidade da função que descreve o imposto de renda, dessa vez, apresentouse uma tabela, equivalente a Tabela 2, mas sem apresentar a coluna do valor a deduzir em cada uma das faixas salariais e a forma como se encontra a lei de formação dessa função.

Antes de a terceira questão ser resolvida, pensava-se que a resposta seria a mesma. Nessa atividade, diferentemente do que ocorreu na anterior, a professora (primeira autora) teve que auxiliar os alunos no entendimento de como se calcula o imposto de renda a ser pago sem que tenha sido fornecida a parcela do valor a deduzir, como na questão 1. Para tanto, foi escolhido um salário qualquer que estava na segunda faixa salarial da Tabela 2, do Quadro 2. Por exemplo, para um salário mensal fixo de $\mathrm{R} \$ 2.000,00$, o contribuinte paga imposto sobre os $R \$ 96,01$ que excedem os $R \$ 1.903,98$, que é o limitante da primeira faixa. Como na segunda-faixa salarial a alíquota é de $15 \%$, os alunos, com o uso da calculadora, determinavam que o valor mensal pago de imposto por esse contribuinte seria $R \$ 7,20$. Após esse entendimento, as equipes tomaram um salário em específico (escolhido por cada equipe) e calcularam o imposto usando a situação dada na questão 3 e o valor a ser pago considerando as tabelas da questão 1. Depois desse entendimento, todos ficaram se questionando como é feito o cálculo da parcela a deduzir do imposto de renda, conforme fornecido pela Receita Federal.

Após a plenária, a proponente, apresentou como se responderia à questão 1 utilizando as representações analítica e gráfica da função, pois a atividade fora realizada por ambas as equipes, apenas de forma gráfica. Toda essa discussão pode ser realizada tanto em uma turma de EM - pois a ideia intuitiva de continuidade os alunos têm pelo significado literal da palavra - quanto em uma turma de CDI do ES. Se fosse numa aula de CDI da graduação esse seria o momento de formalizar o conteúdo de continuidade de uma função. Como os 
alunos de FCA já passaram por $\mathrm{CDI}$, a professora não precisou definir continuidade, apenas foi relembrada a definição D1 (que era de conhecimento de todos os alunos) e aplicada nas questões 1 e 3 para concluir que a função proposta é contínua nos extremos das faixas salariais. Para se chegar nessa conclusão, os alunos construíram o gráfico no GeoGebra e, a seguir, calcularam o valor das imagens da função nos extremos das faixas salariais. Para tanto, foi necessário apresentarem a representação analítica dessa função $I(s)$, a partir de abril de 2015, que é:

$$
I(s)=\left\{\begin{array}{c}
0, \text { se } 0 \leq s \leq 1.903,98 \\
0.075 s-142.80, \text { se } 1.903,98<s \leq 2.826,65 \\
0.15 s-354.80, \text { se } 2.826,65<s \leq 3.751,05 \\
0.225 s-636,13, \text { se } 3.751,05<s \leq 4.664,68 \\
0.275 s-869,36, \text { se } s>4.664,68
\end{array}\right.
$$

independentemente da formulação (questão 1 ou 3). Destaca-se ainda que na plenária a professora, além de mostrar graficamente, usou a definição D1. Dessa forma, foi concluída que a função é contínua em todo seu domínio (como se suspeitava antes de realizar a atividade).

Com relação a questão 2 , que questionava se a nova tabela beneficiou ou não o contribuinte cujo salário fixo mensal é $R \$ 3.600,00$ foi necessário refazer os cálculos para tirar as devidas conclusões. De janeiro a março de 2015, o contribuinte pagou mensalmente $R \$ 3.600 \times 0,225-R \$ 602,96=R \$ 207,04$. De abril a dezembro de 2015, o valor pago pelo contribuinte é $R \$ 3.600,00 \times 0,15-$ $\mathrm{R} \$ 354,80=\mathrm{R} \$ 185,20$. Dessa forma, concluímos que a correção na tabela progressiva favoreceu o contribuinte da questão 2 .

A próxima subseção é destinada a esclarecer como é feito o cálculo da parcela a deduzir do imposto de renda.

\subsection{A evolução da atividade proposta}

A fim de entender como se faz o cálculo da parcela a deduzir da tabela progressiva do imposto de renda foi feita uma ampla pesquisa em websites. 
Nessa busca por resposta, a professora encontrou nos comentários de um site ${ }^{9}$ uma explicação de como é feito esse cálculo. A seguir descrevemos esse procedimento.

O cálculo da parcela a deduzir da tabela progressiva é obtido da seguinte forma:

1) Multiplica-se o valor mínimo da base de cálculo da faixa salarial desejada pela alíquota correspondente dessa mesma faixa salarial;

2) Multiplica-se o valor mínimo da base de cálculo, considerado no passo 1 , pela alíquota da faixa salarial anterior;

3) Faz-se a diferença entre os valores obtidos nos passos 1 e 2, respectivamente;

4) Adiciona-se ao valor obtido no passo 3 a parcela a deduzir da faixa anterior à desejada.

Para exemplificar, vamos encontrar o valor de $\mathrm{R} \$ 636,13$ da Tabela 2 apresentada no Quadro 2.

Passo 1: $R \$ 3751.06 \times 0,225=R \$ 843,988$;

Passo 2: $\mathrm{R} \$ 3751.06 \times 0,15=\mathrm{R} \$ 562,659$;

Passo 3: $R \$ 843,988-R \$ 562,659=R \$ 281,33$;

Passo 4: $R \$ 281,33+R \$ 354,80=R \$ 636,13$.

Para que o leitor perceba a diferença de como é feito o cálculo do imposto a ser pago com e sem o uso da terceira coluna da Tabela 2, tomemos como exemplo o contribuinte, da questão 2 da atividade 2, que tem um salário mensal fixo de $R \$ 3.600,00$ e façamos os cálculos. Inicialmente, calculemos o valor do imposto a ser pago considerando o valor a deduzir da Tabela 2. O valor mensal a ser pago pelo imposto é igual a $R \$ 3.600,00 \times 0,15-R \$ 354,80=R \$ 185,20$. Agora, calculando o imposto sem considerar o valor a deduzir apresentado na Tabela 2. Como o salário de $R \$ 3.600,00$ está na terceira faixa salarial, então até $\mathrm{R} \$ 1.903,98$ não se paga imposto, pagará imposto sobre $\mathrm{R} \$ 3.600,00$ - $\mathrm{R} \$$ $1.903,98=R \$ 1.696,02$; destes, $R \$ 2.826,65-R \$ 1.903,99=R \$ 922,66$ paga-se

${ }^{9}$ http://bonsinvestimentos.com.br/como-calcular-imposto-de-renda-ir-desconto-inss/. Acesso em: 19/06/2016. 
$7,5 \%$ de imposto, ou seja, $R \$ 922,66 \times 0,075=R \$ 69,1995 \approx R \$ 69,20 ;$ o restante $R \$ 773,36$ (dos $R \$ 1.696,02$ ) paga-se $15 \%$ de imposto, ou seja, $R \$$ $773,36 \times 0,15=R \$ 116,00$. Logo, somando o valor a ser pago, referente a segunda e a terceira faixa salarial, resulta que o contribuinte deve pagar $R \$ 69,20$

+ $R \$ 116,00=R \$ 185,20$. Observe que esse valor é exatamente o mesmo obtido anteriormente e de forma muito mais fácil. Logo, os valores da parcela a deduzir que a Receita Federal disponibiliza para o contribuinte são para facilitar/agilizar os cálculos e interpretar de quem queira entender manualmente (pois o programa disponibilizado pela Receita faz os cálculos para o contribuinte) como se fazem as contas do valor a ser pago de imposto.

\section{A ótica da aluna e professora}

Como aluna de Pós-Graduação e professora de CDI há 11 anos, após finalizar esse trabalho e a disciplina de FCA tenho a certeza de que é possível estabelecer muitos elos entre alguns assuntos de Cálculo com a Matemática do EM. Entretanto, essa prática exige que os professores formadores de professores estejam dispostos a enfrentar os novos desafios, saindo de sua zona de conforto e procurando desenvolver estratégias para que exista esse elo entre o ES e o EM.

Nesse contexto, como professora de Cálculo acredito que a disciplina de FCA conseguiu atingir seu objetivo, pois ela propiciou momentos de discussão a respeito de como o Cálculo é ensinado na Universidade e de como é possível trabalhar problemas de Cálculo, vistos no ES e no EM. Para tanto, a abordagem no EM não necessita e nem deve ser a mesma do ES. Durante a disciplina de FCA tivemos a oportunidade de conhecer e desenvolver atividades que podem ser aplicadas nos dois níveis de ensino, dentre elas a questão a respeito de continuidade que foi discutida nesse artigo. Dessa forma, me sinto mais preparada e motivada para, em minhas aulas de Cálculo, apontar/mostrar aos estudantes, os futuros formadores, a conexão existente entre o conteúdo do ES com o EM, em conformidade com SBEM (2013). 
Para tanto é claro que preciso continuamente estar pesquisando/pensando atividades que propiciem tal conexão. Além dessa conexão dos dois níveis de ensino, estou me dispondo a sair da zona de conforto e inserir a metodologia de RP em minhas aulas, essa mudança de postura pode ser interessante aos meus alunos, principalmente para os acadêmicos dos cursos de Licenciatura, pois estarão experimentando uma metodologia diferenciada da tradicional. Pode ser que esses estudantes se inspirem e futuramente insiram em suas práticas pedagógicas a metodologia de RP que é sugerida por documentos oficiais como os Parâmetros Curriculares Nacionais de Matemática tanto do Ensino Fundamental como do Médio (BRASIL, 2000) e das Orientações Curriculares Nacionais para o Ensino Médio (BRASIL, 2006). Essa aspiração está pautada na experiência pessoal, pois tanto como aluna do EM quanto do Superior, sempre fui exposta a aulas do estilo tradicional e minha prática pedagógica também sempre foi tradicional, pois não sabia como aplicar uma metodologia diferenciada, visto que em minha graduação apenas estudei na teoria diferentes metodologias de ensino, mas nunca experimentei como aluna. No momento em que comecei a lecionar, me inspirei nos professores que mais me identifiquei ao longo de minha jornada estudantil. Por isso, acredito que enquanto mais professores universitários não buscarem sair de sua zona de conforto e tentarem inovar as suas práticas, muitos dos professores do EM continuaram apenas replicando as suas experiências, ou seja, adotando o estilo tradicional. De modo algum estou querendo dizer que aulas tradicionais não são boas, mas gostaria de mostrar que podemos diversificar as estratégias utilizadas em sala de aula a fim de melhorar a qualidade do ensino.

Destaco ainda, com relação ao problema identificado e relatado na seção 5.2, que essa autora teve a oportunidade de esclarecer aos colegas e a professora de FCA o equívoco que cometeu e apresentar a solução correta do problema proposto. Julgo que esse feedback tenha sido importante, pois todos tinham se envolvido na resolução do problema proposto e ficaram instigados com as respostas das questões 1 e 3 , da atividade 2, que eram diferentes. Situações 
como essa podem ocorrer no dia a dia de sala de aula, inclusive algumas vezes o professor pode cometer algum erro ao responder algum questionamento de um aluno, mas identificando que houve um erro, o docente deve sempre ter a humildade de pedir desculpas e retomar a discussão, apresentando a resposta correta, para que esse erro não seja repassado adiante por seus alunos aos futuros alunos deles.

\section{Considerações Finais}

Essa prática, inserida na disciplina de FCA, propiciou o reconhecimento, a reflexão e compreensão da conexão possível de ideias fundamentais do Cálculo que podem ser exploradas tanto no ES quanto na Educação Básica.

Com base nas discussões apresentados por Jayakody e Zazkis (2015) com relação à definição de continuidade podemos inferir que o problema associado com a continuidade de uma função pode ocorrer ao estudar a continuidade em um ponto que não pertence ao seu domínio. Nesse ponto, a análise faz sentido se considerar a definição D1, mas não se adotar a definição D2. Essa afirmação corrobora com Ávila (2006) quando ele destaca que:

(...) estamos admitindo que um ponto possa ser descontinuidade de uma função, mesmo que ele não pertença ao domínio de f. A rigor, não deveria ser assim, só deveríamos admitir descontinuidades em pontos pertencentes ao domínio da função. Mas é natural considerar 0 que se passa nas proximidades de pontos de acumulação do domínio de uma função, mesmo que tais pontos não pertençam ao domínio. (ÁVILA, 2006, p.155).

Por fim, com relação às atividades propostas sobre função contínua, ambas poderiam ser trabalhadas nos dois níveis de Ensino, tanto no nível Médio como no Superior.

A questão sobre a função que descreve o imposto de renda foi uma atividade que instigou/motivou os estudantes de FCA a quererem resolver o problema proposto. Uma hipótese para todo esse interesse manifestado pode estar relacionada ao fato de que esse problema é uma situação real, que faz parte 
da vida desses respondentes. Talvez, ao trabalhar no EM ou em um curso de CDI esse problema não seja tão motivador, porque provavelmente a maioria dos estudantes ainda não precise fazer a declaração do imposto de renda, porém ele pode ser desafiador, envolvendo o contexto familiar e social, mostrando aos estudantes a importância deles entenderem como são calculados os impostos pagos pela sociedade.

\section{Agradecimentos}

Agradecemos o apoio da Fundação de Amparo à Pesquisa e Inovação do Estado de Santa Catarina (FAPESC) e dos grupos de pesquisa PEMSA e NEPesTEEM.

\section{Referências}

ANTON, Howard; BIVENS, Irl; DAVIS, Sthephen. Cálculo. Porto Alegre: Bookman, vol. 1, $10^{\mathrm{a}}$ ed., 2014.

AVILA, Geraldo. O Ensino de Cálculo no 2 grau. Revista do Professor de Matemática, n.18, 1991.

ÁVILA, Geraldo. Análise Matemática para Licenciatura. 3ª ed. São Paulo: Editora Blucher. 2006.

BRASIL, Ministério da Educação. Secretaria de Educação Média e Tecnológica. Parâmetros curriculares nacionais para o ensino médio. Brasília: MEC, 2000.

Ministério da Educação, Secretaria da Educação Básica. Ciências da natureza, Matemática e suas Tecnologias (Orientações curriculares para o ensino médio; volume 2) Brasília, 2006,135 p.

. Ministério da Educação, Secretaria da Educação Básica. Base Nacional Curricular Comum. Proposta Preliminar. Segunda Versão (revisada), Brasília, 2016.

CONCORDIDO, Cláudia Ferreira Reis; BARBOSA, Augusto Cesar de Castro. Uma proposta para o ensino de Cálculo Diferencial no Ensino Médio. IV Colóquio Internacional Educação, Cidadania e Exclusão: Didática e Avaliação, Rio de Janeiro, 2015.

DANTE, Luiz Roberto. Formulação e resolução de problemas de matemática: teoria e prática. Editora Ática, São Paulo, 2009. 
GUIDORRIZI, Hamilton Luiz. Um curso de Cálculo. LTC, v.1, 5ae ed, Rio de Janeiro, 2008.

GUEDES, Anderson Guimarães; ASSIS, Márcia Maria Alves de. Cálculo Diferencial e Integral no Ensino Médio: uma análise nas escolas de ensino médio da cidade de Natal/RN. II Encontro Regional de Educação Matemática, Rio Grande do Norte, 2009.

HOUAISS, Antônio; VILLAR, Mauro de Salles; FRANCO; Francisco Manoel de Mello. Dicionário Houaiss de sinônimos e antônimos. Objetiva, Rio de Janeiro, 2003.

JAYAKODY, Gaya; ZAZKIS, Rina. Continuous Problem of Function Continuity. For the Learning of Mathematics 35, 1FLM Publishing Association, Fredericton, New Brunswick, Canada, 2015.

NOGUTI, Fabiane Cristina Höper. Um curso de matemática básica através da resolução de problemas para os ingressantes da Universidade Federal do Pampa Campus Alegrete. 2014, 370 f. Tese (Doutorado em Educação Matemática) - Instituto de Geociências e Ciências Exatas, Universidade Estadual Paulista, Rio Claro.

ONUCHIC, Lourdes de la Rosa. A resolução de problemas na educação matemática: onde estamos? E para onde iremos? Espaço Pedagógico, v.20, n.1, Passo Fundo (RS), p. 88-104, jan/jun. 2013.

POLYA, George. A arte de resolver problemas: um novo aspecto do método matemático. Tradução e adaptação Heitor Lisboa de Araújo. Rio de Janeiro, Interciência, 2006.

SBEM. A formação do professor de Matemática nos cursos de licenciatura: reflexões produzidas pela comissão paritária. Boletim Informativo, n.21, 43p, 2013.

SCHROEDER, Thomas L.; LESTER Jr, Frank K. Developing Understanding in Mathematics via Problem Solving. In: P. R. Trafton (Ed) New Directions for Elementary Schol Mathematics, 1989 Yearbook (pp. 31-42), Reston, VA: NCTM.

STEWART, James. Cálculo. São Paulo: Pioneira Thomson Learning, v.l, 6ª ed., 2009.

TORRES, Terezinha lone Martins; GIRAFFA, Lucia Maria Martins. O Ensino do Cálculo numa perspectiva histórica: da régua de calcular ao MOODLE. Revista Eletrônica de Educação Matemática. V4.1, p.18-25, UFSC: 2009. 